\title{
A Comparative Study of Effectiveness of Honey and Povidone Lodine in Healing of Surgical Wound
}

\author{
Ramanuj Mukherjee ${ }^{1}$, Sudipta Samanta ${ }^{2}$, Avishek Jha ${ }^{3}$, Pran Gopal Sarkar ${ }^{4}$ \\ ${ }^{1}$ Associate Professor, Department of Surgery, R.G. Kar Medical College and Hospital, ${ }^{2}$ Undergraduate Student, R.G. Kar \\ Medical College and Hospital, ${ }^{3}$ Department of Surgery, R.G. Kar Medical College and Hospital, ${ }^{4}$ Professor, Departement of \\ Surgery, R.G. Kar Medical College and Hospital, India
}

Corresponding author: Dr. Ramanuj Mukherjee, 152/A Gopal Lal Tagore Road, Kolkata-700108, India

DOI: http://dx.doi.org/10.21276/ijcmsr.2018.3.4.32

How to cite this article: Ramanuj Mukherjee, Sudipta Samanta, Avishek Jha, Pran Gopal Sarkar. A comparative study of effectiveness of honey and povidone lodine in healing of surgical wound. International Journal of Contemporary Medicine Surgery and Radiology. 2018;3(4):D142-D146.

\section{A B S T R A C T}

Introduction: Honey is a viscous, supersaturated solution derived from nectar modified by the honeybee. Honey has been used as a remedy in wound care and evidences have suggested accelerated wound healing. The aim and objective of the study was to compare the efficacy of honey and povidone iodine in different types of wound management

Material and Methods: A longitudinal prospective study done in R.G. Kar Medical college and Hospital on 100 patients included following inclusion and exclusion criteria and were equally divided in two groups; one received honey dressing and other povidone-iodine. Clinical examination with history, pain scored by visual analog scale (VAS) and wound surface area were noted. Outcome was analysed at 10 days, 1 month and 3 months following intervention.

Result: Mean age group in honey dressing group was 43.8 years and in povidone-iodine group was 43.91 years. Most of them had diabetic ulcers. Outcome in either group was comparable in terms of the etiology $(p=0.993)$. Ulcers at different locations had insignificant effect on outcome in either group $(p=0.836)$. Thus, etiology and location has no significant effect on the dressing material. Diabetes, smoking and alcoholism also had no significant effect in either group ( $p=0.841,0.067$, 0.235 respectively). VAS score for pain was more reduced from baseline in honey dressing group than povidone-iodine group after both 1 and 3 months of intervention which was significant. Surface area of wound was also reduced significantly more in honey dressing group than povidone-iodine group after 1 and 3 months. However, after 10 days of intervention the outcome was comparable and insignificant.

Conclusion: Honey appears to be more effective in wound healing than povidone-iodine.

Key word: Honey, Povidone-iodine, Diabetic Ulcer, Pressure sore, Tegaderm

\section{INTRODUCTION}

Wounds are physical injuries that results in an opening and break of the skin that cause disturbance in the normal skin anatomy and function. They result in the loss of continuity of epithelium with or without the loss of underlying connective tissue. Wound may be produced by physical, chemical, thermal, microbial or immunological insult to the tissues. The process of wound healing consists of integrated cellular or biochemical events leading to the building of structural and functional integrity with regain of strength of injured tissues.

Chronic wounds are a considerable burden to patients and the National Health Service (NHS). Current estimation indicate about 6 million people are suffering from chronic wounds worldwide. ${ }^{1}$ The prevalence of chronic wounds in the community was reported as 4.5 per 1000 population, whereas an acute wound was about 10.5 per 1000 populations. $^{2}$

Some diseases like diabetes, immune-compromised conditions, ischemia and conditions like malnourishment, ageing, local infection, local tissue damage due to burn or gunshot often leads to delay in wound healing. Infection is the major complications of burn injury and is responsible for $50-75 \%$ of hospital deaths. ${ }^{3}$ A lot of people are developing diabetes at a very younger age due to stressful life. It was reported that a lot of children having this chronic and fatal disorder. Long occurrence of these fatal disorders increases the chance of non-healing wounds.

Chronic wounds are non-healing wounds will continue to rise with increasing the population ages, chronic diseases, and the poor nutrition available. Most chronic wounds are ulcers that are associated with ischemia, diabetes mellitus, venous stasis disease, or pressure. About 3 to 6 million people suffer with chronic wound in the United States in which persons are 65 years and older accounting for $85 \%$ of total cases. Non-healing wounds result in enormous health care expenditures, with the total cost estimated at more than $\$ 3$ billion per year. ${ }^{4}$

Diabetes mellitus is one of the most common factors for chronic wound due to metabolic disorders and $2.8 \%$ of the population suffers from this disease throughout the world 
and it may cross $5.4 \%$ by the year 2025 . According to Indian epidemiological data chronic wounds was reported as 4.5 per 1000 population whereas that of acute wounds was nearly doubled at 10.5 per 1000 population. $^{2}$

In America 3-5\% of all hospitalized patients have spinal cord injuries which suffer from ulcers. According to epidemiological data 225,000 spinal cord injury patients in the United States with about 9,000 new patients each year. Approximately 60\% of diabetic patients develop pressure ulcers, and the range of annual cost estimate from $\$ 14,000$ to $\$ 25,000$ per patient for medical, surgical, and nursing care. The national expenditure cost of pressure ulcers is over $\$ 1.3$ billion per year. Overall it is estimated that after 15 years the population will increase from 4 million to over 17 million individuals. Therefore, this health care problem is increasing at a dramatic rate. ${ }^{5}$

In America the cost of institutional care on the same is supposed to be US\$1000 per day while no such estimates are available for Indian institutions, the same demographic study has projected market expenditure of over US $\$ 7$ billion worldwide for provisions of wound healing properties.

In India wound care is very expensive and especially with the diabetic population. The challenge was not only to improve wound care and treatment facilities but also stress on prevention among the population and heath care practitioner. The aim and objective of the study was to compare the efficacy of honey and povidone iodine in different types of wound management

\section{MATERIAL AND METHODS}

Present Longitudinal Non-randomised study was done in R.G Kar Medical College and Hospital, Kolkata on patients attending outdoor and emergency of R.G Kar medical college and hospital in the department of general surgery.

Study period was from January 2016 to Oct 2017. It was done on 100 patients, 50 Patients in each group.

\section{Study parameters}

1. Demographic Parameter: Age

2. Effect of Co-morbidities and habits on dressing technique: Diabetes, Smoking, Alcoholism

3. Outcome at different intervals after dressing: Pain Score by Visual Analog Scale, Surface area of wounds.

\section{Study method}

\section{Inclusion criteria}

- 18 years old patients with chronic wound of duration $>6$ weeks

- Patient presenting with infected wounds were initially treated with daily dressing-cleaning with normal saline and dressing with paraffine gauze along with surgical debridement and oral antibiotics based on bacterial wound culture report.

Exclusion criteria: Patient with postoperative wounds, burn and skin graft donor sites, wound size $>5 \mathrm{~cm}$ in maximum diameter, known allergic to honey or povidone iodine.

Study Technique: In this interventional prospective longitudinal non-randomised study, total 100 patients attending outdoor and emergency of department of surgery of R.G. Kar Medical College and Hospital during the study period was selected according to inclusion and exclusion criteria and divided into two groups with 50 subjects in each group. After written informed consent (Image 1: Patient Consent Form) has been taken and obtaining approval from ethical committee (Image 2: Ethical Approval Form), one group was dressed with honey and the other with povidone iodine. The baseline pain score by VAS and Surface area of the wound and comorbidities and habits were noted. After the intervention was done, the patients were followed up and pain score by VAS and surface area of wound was noted. The parameters as mentioned above were compared and analysed.

\section{STATISTICAL ANALYSIS}

Both descriptive and inferential statics will be used for tabulation, analysis and interpretation.

Statistical measures like mean, SD and proportion as appropriate. In addition, we will consider using chi squared test of independence for categorical outcome variables.

\section{Study tools}

1. Routine Blood Investigations: Complete hemogram, bleeding time, clotting time, fasting and postprandial blood sugar, serum Urea and Creatinine,

2. ECG, Chest X-ray

3. Limb X-ray and Doppler study where required

4. Visual Analogue scale for scoring pain

\section{RESULTS}

\section{Age group}

Mean age was $43.8(\mathrm{SD}=7.56)$ years in the honey group and $43.91(\mathrm{SD}=6.02)$ years in the povidone iodine group.

\section{Distribution of patients according to type of wound in the study groups}

The study comprises of Diabetic foot ulcer, pressure bed sore, Traumatic ulcer and venous ulcer. All types of ulcers are comparatively equally divided in both groups. They are comparable as p value (0.993) is insignificant.

\section{Distribution of patients according to location of ulcer}

In our study we had ulcers at leg, ankle, foot, Dorsum, sole,

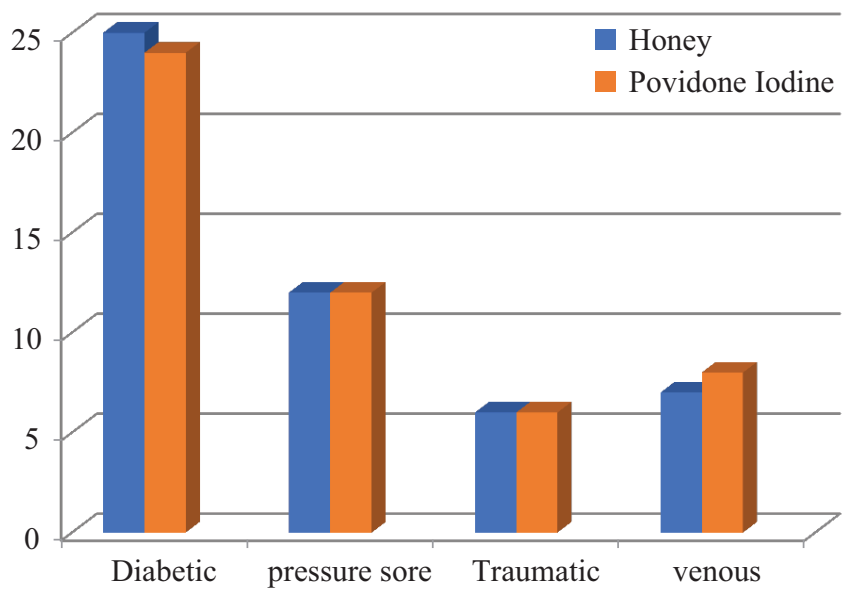

Figure-1: Bar Diagram showing distribution of patients according to type of wounds in study groups 


\begin{tabular}{|c|c|c|c|c|}
\hline \multirow[t]{2}{*}{ Outcome } & \multicolumn{2}{|c|}{ Analysis at 1 month } & \multicolumn{2}{|c|}{ Analysis at 3 months } \\
\hline & Honey group & Povidone iodine gr & Honey group & Povidone iodine group \\
\hline Pain Score (VAS) ${ }^{a}$ & 2.42 & 2.58 & 0.16 & 0.76 \\
\hline Surface Area $\left(\mathrm{cm}^{2}\right)^{b}$ & 1.98 & 2.42 & 0.27 & 0.51 \\
\hline
\end{tabular}

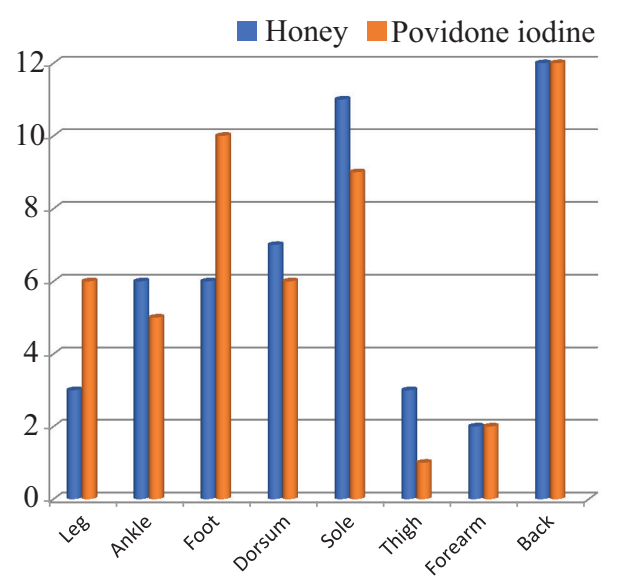

Figure-2: Bar diagram showing distribution of patients according to location of ulcer

thigh, forearm, back. The $\mathrm{p}$ value $(0.836)$ shows the outcome in the study groups was insignificant after comparing different locations of ulcer

Distribution and Comparing study groups by $p$-values in terms of different co-morbidities and habits

In our study we considered and compared Diabetes, smoking and alcoholism in the two study groups. The results were insignificant since $\mathrm{p}$ value was $>0.005$. The $\mathrm{p}$ values were 0.841, 0.067, 0.235 for diabetes, smoking and alcoholism respectively in both groups.

\section{Distribution according to outcome at the different time}

\section{milestone}

The outcome was observed in terms of the pain score assessed by Visual Analog Scale (VAS) and reduction of surface area (rSA) at 10 days, 1 month, 3 months after the study. The analysis showed insignificant changes at 10 days. The changes show significant difference in outcomes with honey dressing and povidone-iodine dressing at 1 month and 3 months after the study.

\section{DISCUSSION}

Majority of the subjects $50 \%$ in the honey dressing group and $52 \%$ in the povidone iodine dressing group- were having chronic wound due to diabetic foot. WHO estimated that 347 million people worldwide suffer from diabetes. ${ }^{6}$ Diabetes currently affects more than 62 million Indians, which is more than $7.1 \%$ of the adult population. ${ }^{7}$ The life time foot ulcer risk is $25 \%$ in diabetes. ${ }^{9}$

We had used numerous strategies to treat wound infections, including topical and systemic administration of antibiotics and various antiseptic agents like Povidone-Iodine to kill bacteria or inhibit their growth. Decisions regarding choice of wound treatment involve two basic considerations:
(1) how safe is the treatment and (2) how effective is the treatment. ${ }^{9}$ Around 1650 BC, Egyptians were the first to use honey as a component in the topical treatment of wounds. ${ }^{10}$ Honey is the most ancient wound dressing known, and it has continued to be used throughout the ages. ${ }^{11}$ Dioscorides (c.50 AD) wrote of honey being 'good for sunburn' and 'for all rotten and hollow ulcers', and its usage has continued into present-day folk-medicine. It is used as a traditional therapy in Ghana for infected leg ulcers. ${ }^{12}$ It is still being used as a dressing material for burn wounds, decubitus ulcers, gunshot wounds and wound dehiscence. It enhances auto debridement by absorbing oedematous fluid around the ulcer margins and promotes granulation tissue formation and epithelization. ${ }^{13}$ This study was conducted over a period of one and half year and included 100 patients. The age group of patients was almost similar in the both the groups. These patients were divided into two groups, of which the first group (Group-A) dressing of chronic ulcer was done by honey and in the second group (Group-B) dressing of chronic ulcer was done by betadine (povidone iodine). In Group- $\mathrm{A}, 86 \%$ patient (43 cases) showed improvement in their wound, while 14\% patient $(7$ cases $)$ did not have any significant changes in their wound. In Group-B, 50\% patients (25 cases) showed improvement of their wound, while $50 \%$ patients (25 cases) did not show any significant changes. Thus, honey had significantly better wound healing effect when compared with betadine.

Several authors have reported that Honey enhances wound healing rate, compared to other conventional or topical application in a variety of clinical conditions, namely burns chronic wounds, infected surgical wounds and pressure ulcer. In 1999 Krammer conducted a review of the clinical trials in which povidone iodine was used for cleaning, irrigating and dressing wounds. He concluded that povidone iodine did not effectively promote good wound healing and did not reduce bacteriological wound infection. ${ }^{14}$

Our results with honey were similar to reports in literature showing rapid healing with the application of honey. ${ }^{15}$ Moreover, Honey caused no adverse reaction. Hamdy et al. reported that the number of microorganisms and bacterial species decreased by $50-100 \%$ by application of honey on chronic infected wounds. ${ }^{16}$

Various authors reported mild or no pain at all during dressing change with honey as compared to other treatments. ${ }^{17,18}$

In our study, percentage of the subjects in the honey dressing group achieved complete healing of chronic wound at the six weeks. Methi et al. reported similar finding by conducting a meta- analysis to evaluate the efficacy of topical application of honey in observational studies as well as in clinical trials in the treatment of wounds. Most of the subjects reported complete healing within 4-12 weeks in clinical trial and 
within 2-9 weeks in observational studies. ${ }^{19}$

The present randomised trial is unique in the sense that the salutary effects of honey have been combined with those of "moist occlusive" dressing. Occlusion of a wound cavity with semipermeable membrane retains the moisture of wound exudates and serves as a moisture retentive dressing. ${ }^{20}$ Evaporation of exudates through an open dressing, namely gauze and cotton leads to cooling, desiccation, and dehydration of surface cells. The mitotic rate of healing cells is diminished at lower body temperature. ${ }^{21}$ Moreover, the layer of dehydrated dead cells on the top of wounds cavity serves as a good food for microbes hampering healing. These adverse effects of open dressing are averted with the application of occlusive dressing. The occlusion can be achieved with the help of semipermeable polyurethane or hydrocolloid dressing. ${ }^{21}$

A meta-analysis on trials comparing hydrocolloid occlusive dressing versus paraffin gauze and cotton dressing demonstrated significant better healing with occlusive dressing. The odd ratio of healing with hydrocolloid dressing was 1.72 compared to conventional paraffin gauze dressing (i.e. $72 \%$ more wounds healed completely with hydrocolloid dressing than with conventional paraffin gauze dressing. ${ }^{21}$ This meta-analysis confirmed the beneficial effects of moisture retention occlusive dressing in terms of complete healing of chronic wounds.

The good results observed in the honey treated group may be combined effect of honey and tegaderm occlusive dressing. Tegaderm offered an opportunity to inspect the wound cavity without the need for disturbing the dressing. It provides an occlusive environment in which honey could exert its full beneficial effect as entire honey poured into the cavity remained available to the healing cells. When honey application to a wound is covered with gauze or cotton, most of it gets absorbed in the gauze and is not available to healing cells. Moreover, polymorphs and macrophages immigrating into the wound cavity liberate growth factors essential for healing (i.e., epidermal growth factor, fibroblast growth factor and vascular endothelial growth factor). These are retained in the wound cavity by an occlusive film like Tegaderm allowing them to exert their full biological activity. ${ }^{22}$ In the conventional dressing with gauze and cotton, the wound cavity is deprived of large fractions of these essential molecules as they get absorbed in gauze and cotton, losing their biological activity.

In the western world, most wound clinics do not recommend the use of povidone iodine application on clean wounds. However, in India many physicians and nurses frequently use povidone even in clean wounds. The present study demonstrates that the rate of wound healing with povidone iodine and Tegaderm was much slower than achieved by the honey treated group.

\section{CONCLUSION}

Honey dressing is more effective as compared to povidone iodine dressing in achieving complete healing, reducing wound surface area and pain, and increasing comfort in subjects with chronic wounds.

\section{REFERENCE}

1. KUMAR, S. M., et al. Triphala incorporated collagen sponge-a smart biomaterial for infected dermal wound healing. Journal of Surgical Research 2010;158 (1): 162170

2. Gupta N, Gupta SK, Shukla VK, Singh SP. An Indian community based epidemiological study of wounds. Journal of Wound Care. 2004. 13(8): 323-325.

3. James, G. A., et al. Biofilms in chronic wounds. Wound Repair and Regeneration 2008;16 (1):27-44.

4. Matthews, K. H., et al. Gamma-irradiation of lyophilised wound healing wafers. International Journal of Pharmaceutics 2006;313(1-2):78-86.

5. Diegelmann, R. F., Evans, C. M. Wound healing: an overview of acute, fibrotic and delayed healing. Frontiers in Bioscience 2004;9 (1):283-289.

6. Gale, Jason (November 7,).” India's Diabetes Epidemic cuts Down Millions Who Escape Poverty' Bloomberg Retrieved 8 June 2012.

7. Diabetes can be controlled in 80 Percent of cases in India. IANS news BIharprabha.com

8. Katsilambros N, Tentolouris N, Tsapogas P, Dounis E. Atlas of Diabetic foot. Chichester, UK: WileyBlackwell 2003

9. Robert IBurks. Povidone-iodine solution in wound treatment. Physther 1998; 78(2): 212-218.

10. B. P. Mwipatayi, D. Angel, J. Norrish, M. J. Hamilton, A. Scott, and K. Sieunarine, The use of honey in chronic leg ulcers: a literature review. Primary Intention 2004; 12(3):107-108, 110-112,

11. umla A, Lulat A. Honey - a remedy rediscovered. J R Soc Med 1989; 82(3): 384-5.

12. Gunther RT. The Greek herbal of Dioscorides. New York: Hafner, 1934. Re- printed 1959.

13. Shukrimi A, Sulaiman AR, Halim AY, Azril A. A comparative study between honey and povidone iodine as dressing solution for Wagner type II diabetic foot ulcers. Medical Journal of Malaysia 2008; 63(1): 44-6.

14. Kramer SA. Effect of povidone- iodine on wound healing: a review. J vasc nurs 1999; 17 (1):17-23.

15. Efem SEE. clinical observations on the wound healing properties of honey. Br J surg 1988; 75:679-681.

16. Hamdy MH, El Banby MA, Khakifa KL, Gad EM (1988) The antimicrobial effect of honey in the management of septic wounds proceedings of the fourth international conference on apiculture in tropical climates, Cairo, Egypt 6- 10 November London, UK; International Bee Research Association.

17. Mphande AN, Kilowe C, Phalira S, Jones HW, Harrison WJ. Effects of honey and sugar dressing on wound healing. J wound care 2007; 16 (7);317-319.

18. Subrahmanyam M. Topical application of honey in the treatment of burns.Br J surg 1991; 78(4):497-498.

19. Medhi B, Puri A, Upadhyay S, Kaman L(2008) Topical application of honey in the

20. Ateyeh BS, Al-Amm CA, El-Musa KA, Sawwaf A, Dham R. The effect of moist and moist exposed dressing on healing and barrier function restoration of partial thickness wounds. Eur J Plast surg 2003; 26(3):5-11.

21. Sing A, Halder S, Menon G, Chumber S, Misra MC, Sharma LK, Srivastva A. Meta- analysis of randomized 
controlled trials on hydrocolloid occlusive dressing in the healing of chronic wounds. Asian J surg 2004;27 (4):326-332.

22. Kwong YL, Chung $\mathrm{CH}$. The use of tegaderm transparent dressing in the outpatient management of partial thickness burns. J Hong Kong Med Assoc 1985; 37(4):28-32.

Source of Support: Nil; Conflict of Interest: None

Submitted: 22-11-2018; Accepted: 09-11-2018; Published online: 30-12-2018 